\title{
Catabolismo de sacarose durante a mobilização do galactomanano e sua importância na estratégia de sobrevivência de plântulas de Sesbania virgata (Cav.) Pers.
}

\author{
Fábio Reis Dalle Molle ${ }^{1}$ e Marco Aurélio Silva Tiné 2,3
}

Recebido: 14.08.2008; aceito: 16.04.2009

\begin{abstract}
Sucrose catabolism during galactomannan mobilisation and its importance in the survival strategy of Sesbania virgata (Cav.) Pers. plantlets). Seeds of Sesbania virgata have galactomannan as a storage polysaccharide in the endosperm. During mobilization, the degradation products are assimilated by the cotyledons which later supply this carbon source to the embryo. Sucrose is of prime importance in this source and sink relation between the organs. In the present work, the importance of the storage galactomannan in the establishment of plantlets of Sesbania virgata was investigated following the study of survival of plantlets with or without endosperm, as well as the diuturnal variations of the sucrose catabolism enzymes activity. The plantlets grown in the darkness with endosperm survived 16 days longer than the plantlets without the storage organ. Independent variations among the enzymes were detected, suggesting that the different enzymes are engaged in different physiological processes and, although sucrose is their common substrate, they take part in independent metabolic pathways.
\end{abstract}

Key words: invertase, source-sink relations, storage, sucrose synthase

RESUMO - (Catabolismo de sacarose durante a mobilização do galactomanano e sua importância na estratégia de sobrevivência de plântulas de Sesbania virgata (Cav.) Pers.). Sementes de Sesbania virgata possuem galactomanano como polissacarídeo de reserva no endosperma. Durante a mobilização, os produtos de degradação são absorvidos pelos cotilédones que, posteriormente, fornecem esse carbono ao eixo embrionário. A sacarose tem um papel fundamental nesta relação de fonte e dreno entre os órgãos. Neste trabalho, a importância da reserva de galactomanano no estabelecimento das plântulas de Sesbania virgata foi investigada através de estudo de sobrevivência de plântulas com e sem endosperma, assim como as variações diuturnas na atividade das enzimas de catabolismo de sacarose. As plântulas crescidas no escuro com endosperma sobreviveram 16 dias a mais que as plântulas sem endosperma. Foram observadas variações independentes entre as enzimas, sugerindo que as diferentes enzimas participam de diferentes processos fisiológicos e, embora tenham a sacarose como substrato em comum, participam de vias metabólicas independentes.

Palavras-chave: invertase, relações fonte-dreno, reserva, sacarose sintase

\section{Introdução}

Sesbania virgata (Cav.) Pers. é uma leguminosa sub-tropical arbustiva que atinge cerca de $6 \mathrm{~m}$ de altura e que possui um comportamento fotossintético típico de plantas pioneiras associado ao crescimento rápido. Desenvolve-se naturalmente em terrenos úmidos e associa-se com Azorhizobium spp (Chaves et al. 2003), ocorrendo com frequencia em ambiente ciliar (Pott \& Pott 1994). As sementes desta espécie acumulam nas paredes das células do endosperma um polissacarídeo de reserva de parede celular denominado galactomanano (Buckeridge \& Dietrich 1990). Alguns trabalhos sobre a mobilização do galactomanano nesta espécie foram publicados sob a sinonímia Sesbania marginata Benth., mas atualmente admite-se o nome Sesbania virgata como sendo o nome correto (anterior) da espécie.

A degradação do galactomanano em sementes com endosperma vem sendo estudado há bastante tempo (Bewley \& Black 1978) e o modelo proposto para a mobilização sugere que o galactomanano é completamente hidrolisado após a germinação até seus monossacarídeos constituintes, que são então absorvidos pelo embrião em crescimento e subsequentemente utilizado como fonte de carbono e energia para muitos processos metabólicos no embrião (Bewley et al. 1983, Bewley \& Black 1994).

1. Programa de Pós-Graduação em Biodiversidade Vegetal, Instituto de Botânica

2. Instituto de Botânica, Seção de Fisiologia e Bioquímica de Plantas, Caixa Postal 3005, 01061-970 São Paulo, SP, Brasil

3. Autor para correspondência: marco.tine@gmail.com 
Embora o mecanismo bioquímico da degradação do galactomanano já tenha sido estudado em Sesbania virgata (Buckeridge \& Dietrich 1996), sabe se pouco sobre o transporte de carbono entre as partes da plântula. O processo de mobilização do galactomanano de sementes de Sesbania virgata é iniciado no segundo dia de embebição e atinge o seu máximo logo no terceiro dia. Após cinco dias do início da embebição, o endosperma já está completamente degradado e os cotilédones se desprendem da testa da semente (Tonini et al.2006, 2007) e iniciam sua expansão, tornando-se órgãos fotossintéticos logo em seguida.

Reid (1971) verificou um aumento nos teores de sacarose nos cotilédones de Trigonella foenumgraecum durante a mobilização do galactomanano e associou isso à absorção dos produtos de degradação do polissacarídeo. Um aumento na concentração de sacarose nos cotilédones de $S$. marginata foi verificado por Buckeridge \& Dietrich (1996), porém esses autores associaram o fenômeno à degradação dos oligossacarídeos da série rafinósica, que são as primeiras reservas a serem mobilizadas pelas plântulas, antes mesmo que o galactomanano. As duas fontes de carbono da semente de Sesbania virgata, portanto, levam à formação de sacarose, o que torna esse dissacarídeo um importante elemento nas relações de fonte e dreno entre os diferentes órgãos da plântula, como descrito para outras espécies (Farrar et al .2000). A própria disponibilidade de sacarose nos tecidos poderia funcionar como um sinalizador no processo, uma vez que além de fonte de energia, a própria sacarose pode atuar como um regulador direto ou indireto da expressão gênica (Winter \& Huber 2000). Estudar o metabolismo de sacarose neste período tão crítico do ciclo de vida da planta, portanto,é essencial para entender as relações fonte e dreno e a alocação de recursos e uso do carbono na planta.

As principais enzimas do metabolismo de sacarose são a sacarose fosfato sintase (SPS) (EC 2.4.1.14), a sacarose sintase (SuSy) (EC 2.4.1.13) e a invertase (EC 3.2.1.26). A síntese de sacarose é realizada principalmente pela SPS, uma enzima alostérica ativada pela glucose-6-fosfato e inibida pelo ortofosfato (Taiz \& Zeiger 2003). A degradação da sacarose, e conseqüientemente, o estabelecimento do dreno, pode ser realizada tanto pela SuSy quanto pela invertase.

Existem pelo menos duas isoformas de SuSy, sendo ambas citoplasmáticas, solúveis ou podem apresentar-se fortemente aderidas ao complexo de celulose sintase na membrana plasmática ou no cito- esqueleto, dependendo do estado de fosforilação (Sturm \& Tang 1999). Existem pelo menos três isoformas de invertase nos tecidos, as quais diferem entre si pela localização celular e propriedades, de modo que é possível distinguir a atividade em cada um dos compartimentos celulares pela propriedade da enzima que se está detectando a atividade. Uma das isoformas está localizada no vacúolo, é solúvel e possui pH ótimo em torno de 4,6. Outra isoforma está presente na parede celular, é insolúvel e também possui $\mathrm{pH}$ ótimo em torno de 4,6. A terceira isoforma está localizada no citoplasma, é solúvel e possui $\mathrm{pH}$ ótimo em torno de 7,0. Alterações das atividades das enzimas de degradação da sacarose por expressão antisense em cenoura (Sturm \& Tang 1999) mostraram efeitos distintos na formação do órgão de reserva como redução do acúmulo de carboidratos, redução do crescimento do órgão de reserva e alteração da razão raiz:parte aérea.

$\mathrm{O}$ presente trabalho se propõe a investigar as relações fonte e dreno de sacarose nas plântulas de $S$. virgata em crescimento com o estudo das atividades das enzimas de degradação da sacarose durante a mobilização do galactomanano. Para isso, foram mapeadas as atividades das enzimas de degradação de sacarose ao longo do terceiro dia de embebição da semente, momento de maior mobilização do galactomanano. Também, a fim de demonstrar a importância do galactomanano como estratégia para as etapas pós-germinativas, a sobrevivência da plântula foi investigada na ausência da fotossíntese.

\section{Material e métodos}

Obtenção e cultivo das plântulas - As sementes foram obtidas de plantas cultivadas sob condições naturais nos jardins do Instituto de Botânica de São Paulo, Brasil. As sementes foram individualmente escarificadas com o auxílio de uma lixa. A seguir foram colocadas em placas de Petri (dez sementes por placa) contendo $15 \mathrm{~mL}$ de água e mantidas a 25 ${ }^{\circ} \mathrm{C}$, sob luz fluorescente com fotoperíodo de 12 horas. Nessas condições $100 \%$ das sementes mostraram protrusão da radícula. Após sete dias as plântulas foram transferidas para vasos com areia e mantidas em casa de vegetação.

Sobrevivência no escuro - A fim de avaliar a importância do galactomanano na estratégia de sobrevivência na ausência de luz, 360 sementes foram escarificadas e embebidas. Após 24 horas de embebição, 180 sementes foram dissecadas para 
remoção do endosperma. Deste subtotal, metade foi mantida no escuro e outra metade na luz. Outras 180 sementes permaneceram com o endosperma, sendo, novamente, metade mantida no escuro e outra metade na luz. As sementes (intactas ou dissecadas) foram transferidas para vasos de 3 litros contendo uma camada de $5 \mathrm{~cm}$ de areia no fundo, de forma a manter espaço para o crescimento das plântulas. No caso das plântulas serem mantidas no escuro os vasos foram cobertos com papel alumínio. Todos os vasos foram mantidos em casa de vegetação. Para estimativa da massa fresca as plântulas foram coletadas após 3, 9, 15 e 25 dias após o início da embebição. A cada coleta, as plântulas foram pesadas em três grupos de cinco plântulas em balança de precisão. Para estimativa da massa seca as mesmas plântulas foram secas em estufa à $60{ }^{\circ} \mathrm{C}$ durante uma semana e pesadas.

Transporte de $\left[{ }^{14} \mathrm{C}\right]$ sacarose $-\mathrm{A}$ fim de entender a alocação de sacarose durante o estabelecimento da plântula, dois experimentos utilizando $\left[{ }^{14} \mathrm{C}\right]$ sacarose foram realizados em momentos distintos do desenvolvimento. Um experimento foi feito em placa de Petri adicionando sacarose ao meio em que a planta crescia e outro, em um estágio posterior do desenvolvimento, com a planta em vaso injetando sacarose no órgão fotossintetizante.

No primeiro experimento, foi acompanhada a absorção de açúcar a partir do meio. Para isso, três plântulas com sete dias de embebição (cultivadas apenas em placas de Petri, conforme descrito acima) foram transferidas para novas placas contendo $10 \mathrm{~mL}$ de água destilada e $10 \mu \mathrm{L}$ solução de $\left[{ }^{14} \mathrm{C}\right]$ sacarose, e incubadas por dois dias a $25^{\circ} \mathrm{C}$. Após este período as plântulas foram coletadas, secas por prensagem entre folhas de papel em estufa a $60^{\circ} \mathrm{C}$ até a estabilização do peso. Após a secagem as plântulas foram montadas em um cassete de exposição contra um filme fotográfico. Após dois dias de exposição o filme foi revelado.

No segundo experimento, a solução de sacarose foi diretamente injetada no órgão fotossintetizante, uma vez que não havia mais órgão de reserva. Nesse experimento foram utilizadas plantas com 15 dias após início da embebição, já aclimatadas em vaso como descrito no item anterior. Cinco microlitros de uma solução de $\left[{ }^{14} \mathrm{C}\right]$ sacarose $(18520 \mathrm{~Bq})$ foram injetados na seção mediana de um dos cotilédones de cada plântula. Após três dias adicionais de cultivo as plântulas foram coletadas, secas e processadas como descrito anteriormente.

Dosagem de atividade enzimática - Para as análises de atividade das enzimas do metabolismo de sacarose, as sementes escarificadas como descrito acima, foram transferidas para placas de Petri (dez sementes por placa), contendo $10 \mathrm{~mL}$ de água destilada e mantidas sob luz fluorescente por 12 horas a $25{ }^{\circ} \mathrm{C}$. Nessas condições $100 \%$ das sementes mostraram protrusão da radícula.

Após 72 horas de embebição, 15 plântulas foram coletadas em intervalos de 6 horas, da 0 hora até as 20 horas do quarto dia após o início da embebição, separadas em três grupos de cinco plântulas e imediatamente dissecadas para separação do endosperma, cotilédones e eixo embrionário. Durante a coleta o fotoperíodo de 12 horas foi mantido. Após a pesagem dos órgãos (massa fresca), eles foram mantidos a $-80{ }^{\circ} \mathrm{C}$ até a preparação dos extratos.

Cada grupo de cinco endospermas, cotilédones e eixos embrionários das plântulas foi moído em almofariz com $2 \mathrm{~mL}$ de tampão Tris $10 \mathrm{mM} \mathrm{pH} \mathrm{6,5}$ a $4{ }^{\circ} \mathrm{C}$. O extrato bruto foi centrifugado por 3 min a $10.000 \mathrm{~g}$. Para os ensaios da SuSy e das invertases solúveis ácida e neutra, o sobrenadante foi dialisado a $4{ }^{\circ} \mathrm{C}$ contra o mesmo tampão de extração por 4 horas, com trocas de tampão em intervalos de uma hora. Para o ensaio da invertase insolúvel de parede celular, o precipitado da centrifugação foi lavado três vezes com tampão acetato de sódio $50 \mathrm{mM} \mathrm{pH} \mathrm{4,6.}$

A atividade da SuSy foi determinada no sentido de síntese de sacarose, segundo as etapas a seguir:

I - Ensaio da SuSy: $300 \mu \mathrm{L}$ de extrato enzimático, $300 \mu \mathrm{L}$ de tampão de ensaio contendo tampão Tris$\mathrm{HCl} 25 \mathrm{mM} \mathrm{pH}$ 7,5, $40 \mathrm{mM} \mathrm{MgCl}_{2}, 30 \mathrm{mM}$ frutose e $20 \mathrm{mM}$ UDP-glucose. A mistura foi incubada a 30 ${ }^{\circ} \mathrm{C}$ por 20 minutos.

II - Hidrólise da sacarose formada: foram adicionados à mistura resultante da etapa anterior 50 $\mu \mathrm{L}$ de ácido acético $500 \mathrm{mM}$, e $150 \mu \mathrm{L}$ de invertase (Sigma 852 unidades $\mathrm{mL}^{-1}$ ). A mistura foi incubada a $30{ }^{\circ} \mathrm{C}$ por 10 minutos.

III - Dosagem de glucose livre: após a incubação com invertase, a glucose livre foi quantificada pela adição de $100 \mu \mathrm{L}$ de tampão Tris $\mathrm{HCl}$ 1,0 M pH 8,0 e $600 \mu \mathrm{L}$ de solução de dosagem de glucose (LabTest). Nesta etapa, a mistura foi incubada por mais 10 minutos a $30^{\circ} \mathrm{C}$. A absorbância foi determinada a $505 \mathrm{~nm}$.

Condições de ensaio de invertase neutra: a mistura de $200 \mu \mathrm{L}$ de extrato enzimático e $80 \mu \mathrm{L}$ de sacarose $600 \mathrm{mM}$, foi incubada a $30{ }^{\circ} \mathrm{C}$ por 20 minutos, e a seguir fervido por dois min. A glucose livre foi quantificada como descrito acima.

Condições de ensaio de invertase ácida: mistura $200 \mu \mathrm{L}$ de extrato enzimático, $10 \mu \mathrm{L}$ de ácido acético 
$50 \mathrm{mM}$ e $80 \mu \mathrm{L}$ de sacarose $600 \mathrm{mM}$, incubada a 30 ${ }^{\circ} \mathrm{C}$ por 20 min., e a seguir fervida por dois min. Logo após foi adicionado $40 \mu \mathrm{L}$ de tampão Tris $100 \mathrm{mM}$ pH 8,0 para a quantificação de glucose, conforme descrito acima.

Condições de ensaio de invertase insolúvel: mistura de $75 \mathrm{mg}$ de precipitado já lavado, $250 \mu \mathrm{L}$ de tampão acetato de sódio $50 \mathrm{mM} \mathrm{pH} \mathrm{4,6} \mathrm{e} 80 \mu \mathrm{L}$ sacarose 600 $\mathrm{mM}$, foi incubada a $30^{\circ} \mathrm{C}$ por 20 min, e a seguir fervida por dois minutos. Após centrifugação (pulso de 13.000 g), $250 \mu \mathrm{L}$ de sobrenadante foram adicionados a 625 $\mu \mathrm{L}$ de tampão Tris $100 \mathrm{mM} \mathrm{pH} \mathrm{8,0} \mathrm{para} \mathrm{a} \mathrm{quantificação}$ de glucose, como descrito acima.

As análises estatísticas foram determinadas pela análise de variância (ANOVA) utilizando o Winstat para Excel. O teste de diferença entre as médias foi o "least significant diferences" (LSD) com nível de significância de $5 \%$.

\section{Resultados e Discussão}

Os resultados de variação de massa (figura 1) mostram que na luz, o eixo embrionário se desenvolveu tanto na presença quanto na ausência do endosperma. A massa fresca aumenta inicialmente devido à embebição (figura 1A), enquanto a massa seca aumenta somente a partir do $15^{\circ}$ dia (figura 1B). A diferença entre a massa seca do eixo com e sem endosperma foi constante, em torno de 70 miligramas, indicando que essa seria a diferença de massa absorvida a partir do endosperma (figura 1B).

A massa seca das plântulas intactas crescidas no escuro permaneceu constante até o $15^{\mathrm{O}}$ dia. Embora a morfologia dessas plântulas crescidas no escuro seja bastante distinta daquelas crescidas na luz devido ao estiolamento, as massas secas entre os dois tratamentos foram próximas. Somente a partir do $15^{\mathrm{o}}$ dia, a massa seca das plântulas crescidas na luz começou a aumentar devido à fotossíntese enquanto a massa seca da plântula crescida no escuro apresentou leve queda. As plântulas sem endosperma cultivadas no escuro não sobreviveram além do $9^{0}$ dia, e as plântulas intactas mantidas no escuro sobreviveram até o $25^{\circ}$ dia, embora entre o $15^{\circ}$ e o $25^{\circ}$ dia, as plântulas tenham mostrado queda na massa fresca, sugerindo que elas não estavam vigorosas e provavelmente não sobreviveriam além desta data. Essa diferença na sobrevivência de plântulas com e sem endosperma, crescidas no escuro, mostra a importância das reservas de galactomanano na estratégia de desenvolvimento da plântula em condições não ótimas de crescimento.
Reid \& Bewley (1979) já haviam observado que apenas no escuro a reserva de galactomanano de sementes de Trigonella foenum-graecum L. é importante para o estabelecimento do embrião. Mas mesmo na presença de luz, o galactomanano teria uma importante função na embebição da semente e proteção contra a dessecação, já sugerindo um caráter multifuncional para o polissacarídeo (Buckeridge \& Reid 1996, Buckeridge et al.2000). Ou seja, mesmo na presença de luz, o polissacarídeo seria importante no estabelecimento do embrião em outros aspectos além da reserva de carbono como, por exemplo, na absorção de água, uma vez que se trata de uma camada muito hidrofílica que envolve o embrião. Nas condições utilizadas neste experimento, apenas a função de reserva foi avaliada.

Quando as plântulas com sete dias foram incubadas na presença de sacarose marcada (figura 2A-B), foi possível observar marcação em toda a plântula, embora a marcação tenha sido mais intensa na raiz. Por não existir conexão vascular entre cotilédones e endosperma, toda a transferência de carbono entre essas duas partes da semente tem necessariamente que ocorrer por exudação dos carboidratos para o meio por parte do endosperma e absorção pelo embrião (Zambou \& Spyropoulos 1990). Nossos resultados mostram claramente que o embrião possui capacidade de absorver carboidratos do meio, não apenas na forma de produtos de degradação de galactomanano (Bewley \& Black 1978), mas também na forma de sacarose, o que é importante uma vez que a concentração de sacarose aumenta durante a degradação do galactomanano (Reid 1971, Buckeridge \& Dietrich 1996). Por ficar em contato íntimo com o endosperma durante a mobilização do galactomanano, acreditava-se que os cotilédones seriam os responsáveis pela absorção dos produtos de degradação do endosperma (Reid 1971). Pelo modelo proposto (Bewley \& Black 1978, Zambou \& Spyropoulos 1990, Buckeridge et al. 2000), os cotilédones seriam os órgãos responsáveis pela absorção dos carboidratos devido à sua proximidade com a fonte de carbono (endosperma). A figura 2B, no entanto, mostra uma grande incorporação de radioatividade na raiz além da incorporação esperada nos cotilédones, o que sugere uma alta atividade de assimilação de carboidratos também por esse órgão. Alternativamente, a sacarose poderia ser assimilada pelos cotilédones e transportada para a raiz, por esta última ser uma área com alta taxa de crescimento. No momento, não é possível distinguir entre as duas 

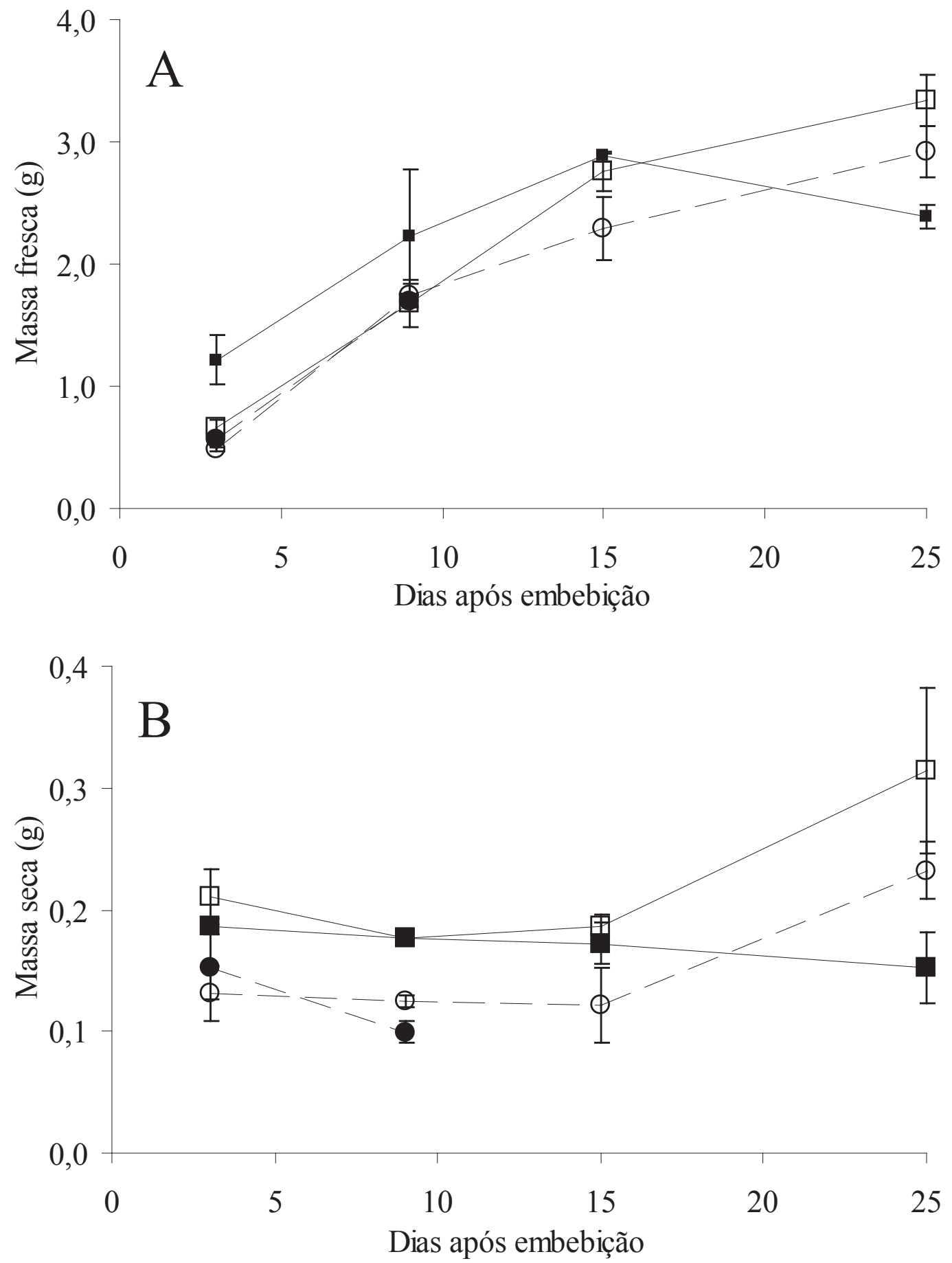

Figura 1. Massa das plântulas de Sesbania virgata durante a fase inicial de desenvolvimento. $\mathrm{A}=$ Massa fresca. $\mathrm{B}=\mathrm{Massa}$ seca. $\bullet=$ escuro sem endosperma, $\bigcirc=$ luz sem endosperma, $\boldsymbol{\square}=$ escuro com endosperma e $\square=$ luz com endosperma $(\mathrm{n}=5)$.

Figure 1. Weight of the Sesbania virgata plantlets in the first developmental stages. A = Fresh weight. $\mathrm{B}=$ Dry weight. - grown in the dark without endorperm, $\mathrm{O}=$ grown in the light without endosperm, $\boldsymbol{\square}=$ grown in the dark with endorperm, $\square=$ grown in the light with endosperm $(n=5)$. 


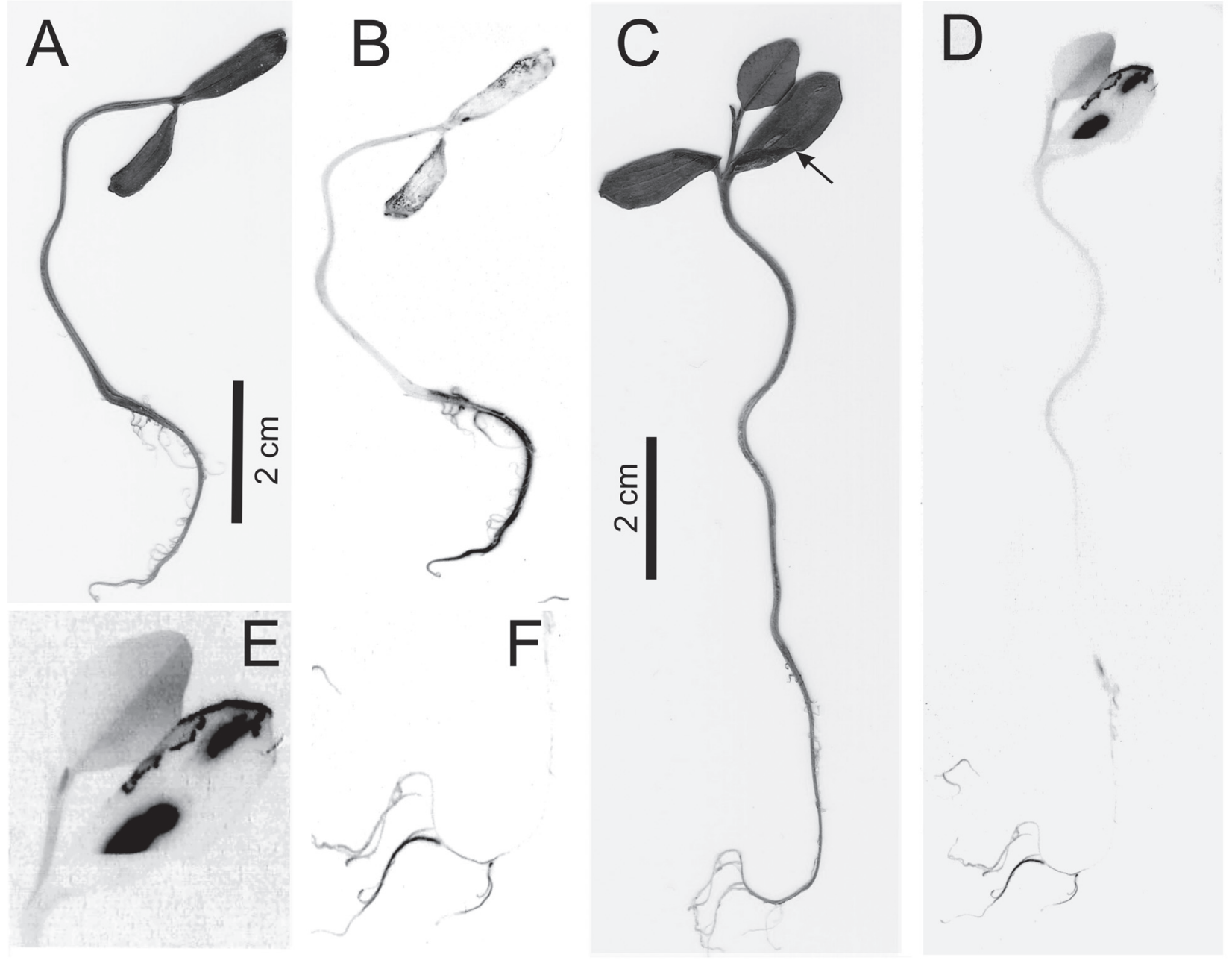

Figura 2. Plântulas de Sesbania virgata após tratamento com solução de $\left[{ }^{14} \mathrm{C}\right]$ sacarose. A. Imagem da plântula seca após a incubação em solução de $\left[{ }^{14} \mathrm{C}\right]$ sacarose. B. Auto-radiografia da plântula mostrada em "A". Note a forte marcação da raiz e dos cotilédones. C. Imagem da plântula seca após injeção da solução de $\left[{ }^{14} \mathrm{C}\right]$ sacarose em um dos cotilédones. A seta indica o cotilédone onde a $\left[{ }^{14} \mathrm{C}\right]$ sacarose foi injetada. D. Auto-radiografia da plântula mostrada em "C". Note a forte marcação onde a $\left[{ }^{14} \mathrm{C}\right]$ sacarose foi injetada e a ausência de marcação no outro cotilédone. E. Detalhe de "D" mostrando a forte marcação no cotilédone tratado, na folha em expansão e no meristema apical. F. Detalhe de "D" mostrando a forte marcação nas áreas de crescimento da raiz.

Figure 2. Plantlets of Sesbania virgata after treatment with a $\left[{ }^{14} \mathrm{C}\right]$ sucrose solution. A. Image of the dry plantlet after incubation in the radio labeled sucrose solution. B. Autoradiography of the plantlet shown in "A". Note the strong labeling in the roots and in the cotyledons. C. Image of the dried plant after injection of the $\left[{ }^{14} \mathrm{C}\right]$ sucrose solution in one of the cotyledons. The arrow shows the injection site. D. Autoradiography of the plantlet shown in " $\mathrm{C}$ ". There is a strong labeling in the $\left[{ }^{14} \mathrm{C}\right]$ sucrose injection site and absence of signal in the other cotyledon. E. Detail of " $D$ ' showing the strong labeling in the injected cotyledon, in the expanding leaf and in the apical meristem. F. Detail of "D" showing the strong labeling in the growing areas of the root. 
alternativas, pois seria necessário um estudo de cinética de absorção.

Após 15 dias de crescimento, as plântulas já completaram sua transição autotrofia-heterotrofia e já estão estabelecidas em vaso com cotilédones fotossinteticamente ativos. A injeção de sacarose radioativamente marcada em um dos cotilédones (figuras 2C-F) mostrou que as partes da planta em crescimento são os principais drenos. $\mathrm{O}$ cotilédone tratado, evidentemente, apresenta uma grande marcação, enquanto que o cotilédone não tratado não aparece na auto-radiografia (figura 2D). A ausência de marcação nesse caso e o fato da fotossíntese já ser funcional nos cotilédones neste estádio de desenvolvimento, sugere que o órgão se apresenta exclusivamente como um exportador de sacarose. Embora três plântulas tenham sido utilizadas, apenas uma representativa das demais é mostrada na figura 2. Os resultados também sugerem que os principais drenos são a folha em expansão e o meristema apical (figura 2E) e as raízes em crescimento (note a marcação nas regiões mais novas da raiz, figura $2 \mathrm{~F}$ ).

Diante da importância da sacarose nas relações fonte e dreno durante a mobilização do galactomanano, foi analisada a variação da atividade das enzimas de metabolismo de sacarose ao longo do quarto dia após embebição, que corresponde ao auge da mobilização do polissacarídeo (figura 3). Quanto à SuSy, a maior atividade foi encontrada nos cotilédones, que permaneceu relativamente constante ao longo do dia, diferentemente do observado no eixo embrionário e no endosperma. Ao meio dia, houve uma queda na atividade no endosperma, concomitante com um aumento no eixo embrionário. Entre as atividades quantificadas, a SuSy foi a enzima com maior diferença entre a fonte de sacarose (endosperma) e o dreno (cotilédones). A julgar pela correlação entre as enzimas, é possível supor que esta enzima seja um elemento chave no fluxo de carbono dentro da planta.

A invertase insolúvel apresentou a atividade mais alta de hidrólise de sacarose entre todas as atividades quantificadas. Também neste caso não houve variação na atividade dos cotilédones ao longo do dia e o eixo embrionário e o endosperma apresentaram a mesma variação (uma queda na atividade ao meio dia seguido de um aumento no fim da tarde). A invertase ácida (vacuolar) também não apresentou variação da sua atividade nos cotilédones, mas houve uma queda da atividade no endosperma e no eixo a partir das 6 horas da manhã, quando as luzes da câmara de crescimento foram acesas. A invertase neutra solúvel (citoplasmática) apresentou as menores atividades entre as isoformas sendo a atividade no endosperma a mais baixa. Não houve variação na atividade ao longo do dia nos cotilédones, mas neste caso também houve uma queda na atividade no endosperma a partir das 6 horas, assim como uma queda na atividade no eixo ao meio dia.

Embora os cotilédones sejam folhas modificadas e, no caso de Sesbania virgata, estejam se desenvolvendo para se tornarem órgãos fotossintéticos, eles ainda não respondem à luz como esperado, pois não há variação nas atividades das enzimas do catabolismo de sacarose como aconteceria em um tecido fotossintetizante (Rascher et al. 2001, Smith \& Stitt 2007). Já no endosperma, que é um órgão senescente e funciona exclusivamente como uma fonte de carboidratos, as atividades variaram, com tendência de atividades mais altas durante a noite. O eixo embrionário, órgão com maior taxa de crescimento, apresentou variações com um padrão mais complexo, com tendência de maior atividade das isoformas de invertase durante a noite, enquanto a SuSy apresenta um pico de atividade ao meio-dia.

O fato dos padrões de variação das atividades serem distintos sugere que as enzimas estão associadas a processos fisiológicos diferentes e independentes, embora todos tenham a sacarose como substrato em comum. A compartimentalização do substrato é um elemento fundamental nessa multifuncionalidade das enzimas (Sturm 1999). Essas enzimas são importantes em diferentes aspectos do metabolismo de sacarose além das relações de fonte e dreno como regulação osmótica e crescimento celular (Sturm \& Tang 1999). Além disso, ao considerarmos que os carboidratos atuam não apenas como substrato para o metabolismo, mas também como moléculas sinalizadoras afetando a expressão de diversos genes (Rolland et al. 2002, Blässing et al. 2005), a importância da atividade de enzimas do catabolismo de sacarose pode ser estendida a diversos outros processos por possibilitar a alteração das concentrações locais de carboidratos.

Cada uma das isoformas da invertase localiza-se em diferentes compartimentos celulares e a sacarose nesses compartimentos pode ter funções distintas. $\mathrm{O}$ vacúolo, por exemplo, é um importante elemento tanto no armazenamento quanto na compartimentalização dos produtos de degradação, sendo essencial nos ciclos de síntese e degradação da sacarose que ocorrem nas células ("ciclos fúteis", Nguyen-Quoc \& Foyer 2001). A existência de diferentes tipos de vacúolos é 


\section{Endosperma}
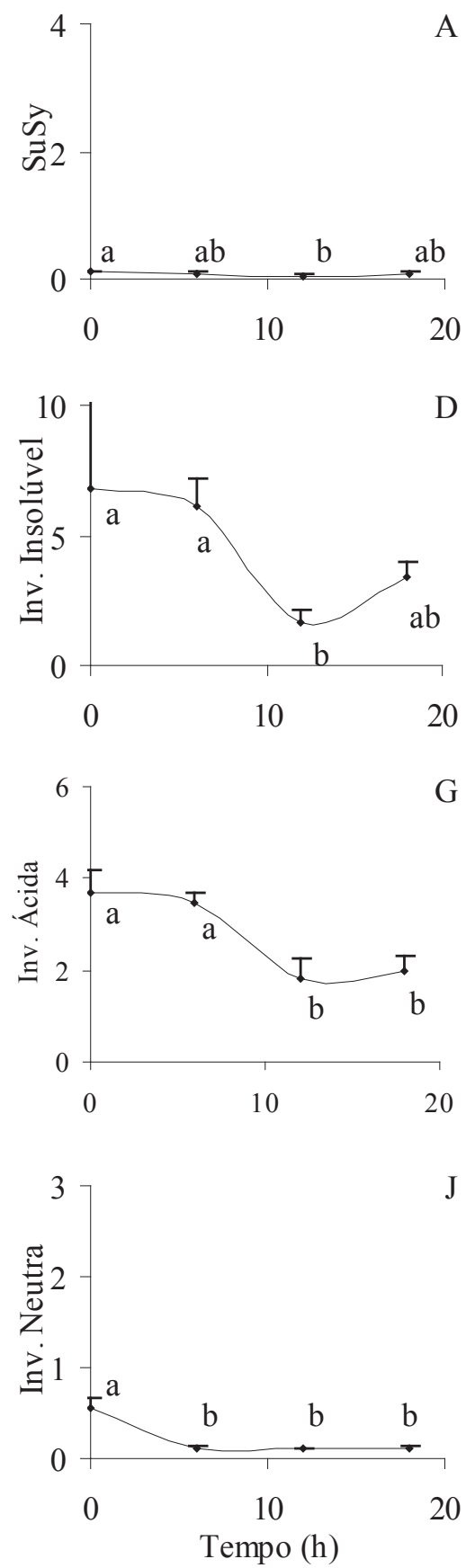

G
Cotilédone
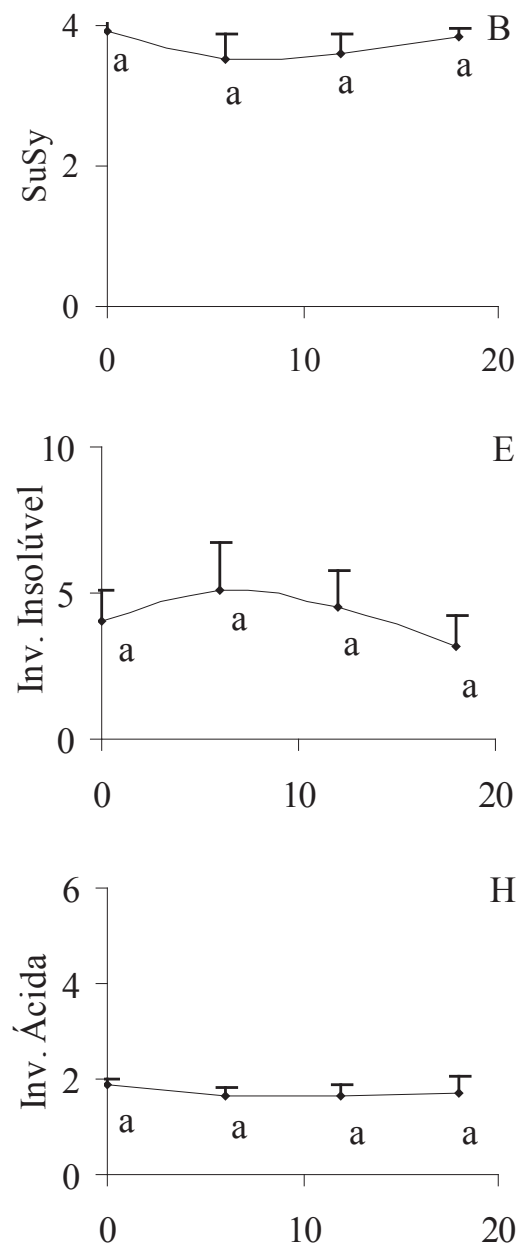

$\mathrm{H}$

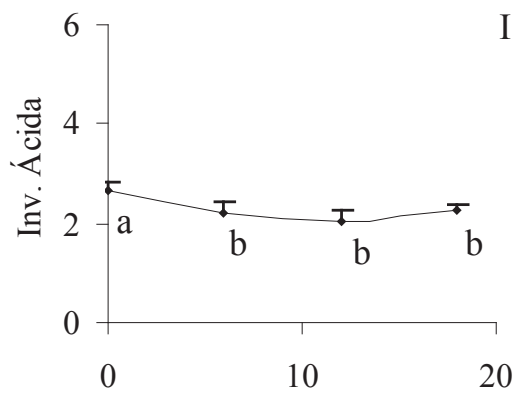

Eixo embrionário
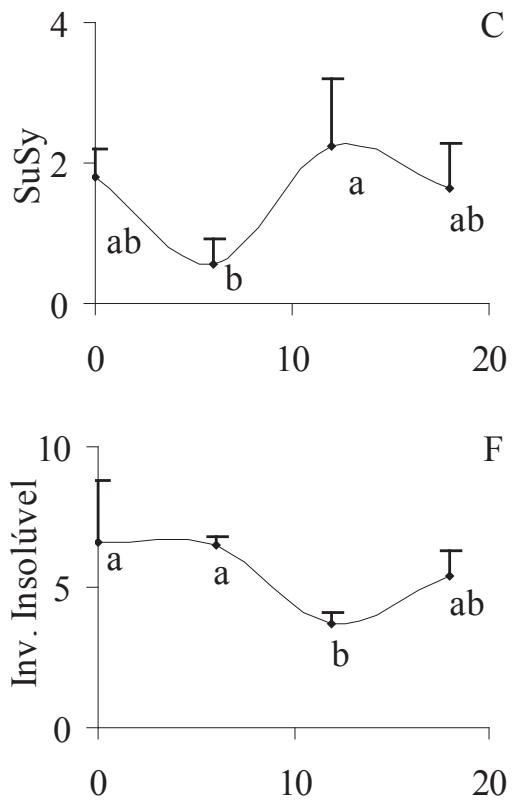
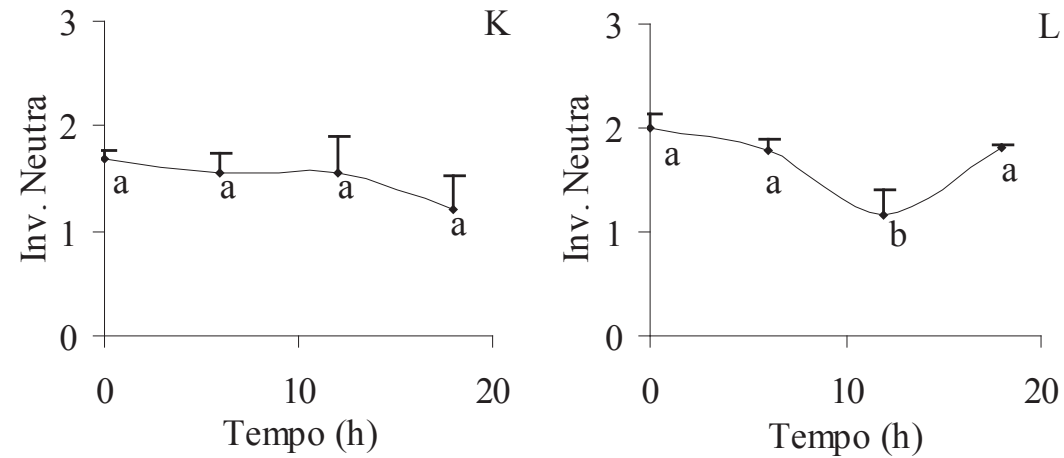

Figura 3. Atividade das enzimas do metabolismo de sacarose nos órgãos de plântulas de Sesbania virgata ao longo do quarto dia após a embebição. A, D, G, J = endosperma; B, E, H, K = cotilédone; C, F, I, L = eixo embrionário; A, B, C = sacarose sintase ( $\mu$ g sacarose min ${ }^{-1}$ $\mathrm{g}^{-1}$ de massa fresca); D, E, F = invertase insolúvel ( $\mu \mathrm{g}$ glucose $\min ^{-1} \mathrm{~g}^{-1}$ de massa fresca); $\mathrm{G}, \mathrm{H}, \mathrm{I}=$ invertase solúvel ácida ( $\mu \mathrm{g}$ glucose $\min ^{-1} \mathrm{~g}^{-1}$ de massa fresca); $\mathrm{J}, \mathrm{K}, \mathrm{L}=$ invertase solúvel neutra ( $\mu \mathrm{g}$ glucose $\min ^{-1} \mathrm{~g}^{-1}$ de massa fresca). Barras verticais representam desvio padrão da média. Letras distintas indicam diferenças estatisticamente significativas $(\mathrm{p}=0,05)(\mathrm{n}=3)$.

Figure 3. Activity of the sucrose metabolism enzymes in the parts of the Sesbania virgata plantlet along the fourth day after imbibition. A, D, G, J = endosperm; B, E, H, K = cotyledon; C, F, I, L = embrionary axis; A, B, C = sucrose synthase $\left(\mu \mathrm{g}\right.$ sucrose min ${ }^{-1} \mathrm{~g}^{-1}$ fresh weight); D, E, F = insoluble invertase ( $\mu$ g glucose $\min ^{-1} \mathrm{~g}^{-1}$ fresh weight); $\mathrm{G}, \mathrm{H}, \mathrm{I},=$ acidic soluble invertase $\left(\mu \mathrm{g}\right.$ glucose min $\mathrm{g}^{-1}$ fresh weight); $\mathrm{J}, \mathrm{K}, \mathrm{L}=$ neutral soluble invertase ( $\mu \mathrm{g}$ glucose $\mathrm{min}^{-1} \mathrm{~g}^{-1}$ fresh weight). Vertical bars represent the standard deviation of the average. Different letters indicate statistically significant differences $(p=0.05)(n=3)$. 
evidenciada por diferentes isoformas de proteínas do tonoplasto, que podem ser utilizadas como marcadores de função desses vacúolos (Jauh et al. 1999).

Neste trabalho, as plântulas crescidas na luz não foram submetidas a uma condição de competição. Nestas condições, ambos os tratamentos de luz produziram plântulas viáveis. A diferença constante de massa entre os tratamentos de luz com e sem endosperma, no entanto, indica que as plântulas que tiveram acesso ao polissacarídeo de reserva possuem uma vantagem de crescimento em uma eventual situação de competição. As diferenças nas condições iniciais de crescimento podem gerar plântulas com desempenho inicial muito distinto, o que poderia levar as taxas de sobrevivência e estabelecimento diferentes. Considerando que a germinação e estabelecimento das plântulas é a etapa mais crítica do ciclo de vida (por ser a etapa de maior mortalidade), fica evidente o valor adaptativo da reserva e a importância do galactomanano na estratégia de vida da espécie.

Embora os efeitos da mobilização do galactomanano sejam percebidos no crescimento da plântula até depois de 25 dias, o processo de degradação das reservas acaba no quinto dia, sendo que o seu auge ocorre após quatro dias de embebição (Buckeridge \& Dietrich 1996). O estudo das relações fonte e dreno durante a degradação do galactomanano é essencial para a compreensão da importância das reservas na estratégia de sobrevivência da plântula, e o metabolismo de sacarose é uma peça chave nessas relações.

\section{Agradecimentos}

À FAPESP pela bolsa concedida ao primeiro autor. A Naira Brasil de Freitas Siqueira e a Luciana de Moraes Gutierrez pelo auxílio no cultivo das plântulas.

\section{Literatura citada}

Bewley, J.D. \& Black, M. 1978. Physiology and Biochemistry of seeds in relation to germination. Vol I e II. Springer-Verlag, Berlin.

Bewley, J.D. \& Black, M. 1994. Seeds: Physiology of development and germination. 2 ed. Plenum Press, New York.

Bewley, J.D., Leung, D.W.M. \& Ouellette, F.B. 1983.The cooperative role of endo- $\beta$-mannanase, $\beta$-mannosidase and a-galactosidase in the mobilization of endosperm cell wall hemicellulases in germinated lettuce seed. Recent Advances in Phytochemistry 17: 137-152.
Blässing, O.E., Gibon, Y., Günther, M., Höhne, M., Morcuende, R., Osuna, D., Thimm, O., Usadel, B., Scheible, W. \& Stitt, M. 2005. Sugars and circadian regulation make major contributions to the global regulation of diurnal gene expression in Arabidopsis. The Plant Cell 17: 3257-3281.

Buckeridge,M.S.\& Dietrich,S.M.C. 1990.Galactomannan from Brazilian legume seeds. Revista Brasileira de Botânica 13: 109-112.

Buckeridge,M.S.\& Dietrich,S.M.C. 1996. Mobilisation of the raffinose familyoligosaccharides and galactomannan in germinating seeds of Sesbania marginata Benth. (Leguminosae-Faboideae). Plant Science 117: 33-43.

Buckeridge, M.S. \& Reid, J.S.G. 1996. Major cell wall storage polysaccharides in legume seeds: Structure, catabolism and biological functions. Ciência e Cultura 48: 153-162.

Buckeridge, M.S., Tiné, M.A.S., Santos, H.P. \& Lima, D.U. 2000. Polissacarídeos de reserva de parede celular em sementes, estrutura, metabolismo, funções e aspectos ecológicos. Revista Brasileira de Fisiologia Vegetal 12: 137-162.

Chaves, L.L.B., Carneiro, J.G.A., Barroso, D.G. \& Leles, P.S.S. 2003. Efeitos da inoculação com rizóbio e da adubação nitrogenada na produção de mudas de Sesbania em substrato constituído de resíduos agroindustriais. Revista Árvore 27: 443-449.

Farrar, J., Pollock, C.\& Gallagher, J. 2000. Sucrose and the integration of metabolism in vascular plants. Plant Science 154: 1-11.

Jauh, G.Y., Phillips, T.E. \& Rogers, J.C. 1999. Tonoplast Intrinsic Protein Isoforms as Markers for Vacuolar Functions. The Plant Cell 11: 1867-1882.

Nguyen-Quoc, B. \& Foyer, C. H. 2001. A role for futile cycles involving invertase and sucrose synthase in sucrose metabolism of tomato fruit. Journal of Experimental Botany 52: 881-889.

Pott,A. \& Pott, V. 1994. Plantas do pantanal. EMBRAPASPL, Brasília.

Rascher, U., Hutt, M., Siebke, K., Osmond, B., Beck F., \& Luttge U. 2001. Spatiotemporal variation of metabolism in a plant circadian rhythm: The biological clock as an assembly of coupled individual oscillators. Proceedings of the National Academy of Sciences 98: 11801-11805.

Reid, J.S.G. 1971. Reserve carbohydrate metabolism in germinating seeds of Trigonella foenum-graecum $\mathrm{L}$. (Legum.). Planta 100: 131-142.

Reid, J.S.G. \& Bewley, J.D. 1979. A dual role for the endosperm and its galactomannan reserves in the germinative physiology of fenugreek (Trigonella foenum-graecum L.) an endospermic legume seed. Planta 147: 145-150. 
Rolland,F., Moore, B. \& Sheen, J. 2002. Sugar sensing and signalling in plants. The Plant Cell (suplemento):185205.

Smith, A.M. \& Stitt, M. 2007. Coordination of carbon supply and plant growth. Plant, Cell and Environment 30: 1126-1149.

Sturm, A. 1999. Invertases. Primary structures, functions, and roles in plant development and sucrose partitioning. Plant Physiology 121: 1-7.

Sturm, A. \& Tang, G.Q. 1999. The sucrose-cleaving enzymes of plants are crucial for development, growth and carbon partitioning. Trends in plant science 4: 401-407.

Taiz, L. \& Zeiger, E. 2003. Photosynthesis: Carbon reactions. In: L. Taiz \& E. Zeiger (eds.). Plant Physiology. Sinauer Associates, Sunderland, pp. 145168.
Tonini, P.P., Lisboa, C.G.S., Freschi, L.,'Mercier, H., Mazzoni-Viveiros, S.C.\& Buckeridge, M.S. 2006. Effect of abscisic acid on galactomannan degradation and endo- $\beta$-mannanase activity in seeds of Sesbaniavirgata (Cav.) Pers. (Leguminosae). Trees 20: 669-678.

Tonini,P.P., Lisboa, C.G.S., Silva, C.O., Mazzoni-Viveiros S.C. \& Buckeridge, M.S. 2007. Testa is involved in the control storage mobilisation in seeds of Sesbania virgata (Cav.) Pers., a tropical legume tree from the Atlantic Forest. Trees 21: 13-21.

Winter, H. \& Huber, S.C. 2000. Regulation of sucrose metabolism in higher plants: localization and regulation of activity of key enzymes. Critical Reviews in Plant Sciences 19: 31-67.

Zambou, K. \& Spyropoulos, C.G. 1990. D-Galactose uptake by fenugreek cotyledons. Plant Physiology 93: 1417-1421 